\title{
Moderate mitral stenosis in pregnancy: the haemodynamic impact of diuresis
}

\author{
A Siva, A M Shah
}

Heart 2005;91:e3 (http://www.heartjnl.com/cgi/content/full/91/1/e3). doi: 10.1136/hrt.2004.053017

A case of asymptomatic, newly diagnosed, moderate mitral stenosis in a 27 year old pregnant woman is described. A conservative management strategy with regular cardiac assessment was adopted and the patient remained well. Routine transthoracic echocardiography at 36 weeks' gestation showed the development of severe pulmonary hypertension with right ventricular pressure overload, which was successfully treated with oral diuretics resulting in rapid normalisation of pulmonary pressure. Mitral stenosis in pregnancy and its management in pregnancy are briefly discussed.

A 27 year old Algerian woman who was 13 weeks into her second pregnancy was referred to the cardiology clinic after being found to have a murmur at her antenatal visit. She had no cardiac symptoms or cardiac history but had miscarried at 10 weeks' gestation in her first pregnancy. Examination showed her to be in sinus rhythm with no signs of heart failure. She had the physical signs of mitral stenosis with a loud first heart sound and a low pitched mid diastolic murmur. Transthoracic echocardiography confirmed moderately severe mitral stenosis with an estimated valve area of $1.3 \mathrm{~cm}^{2}$ and anatomical features consistent with a rheumatic cause. The estimated pulmonary artery systolic pressure was 35-40 $\mathrm{mm} \mathrm{Hg}$. Left ventricular function was normal and there was slight left atrial dilatation. The patient was managed conservatively through pregnancy with regular review and repeat transthoracic echocardiography. At 36 weeks' gestation, the patient attended a routine review having remained well throughout pregnancy.

Examination showed a mild rise of the jugular venous pressure at $3 \mathrm{~cm}$ above the clavicle and mild ankle oedema. Transthoracic echocardiography showed no change in her mitral stenosis (mitral valve stenosis of $1.4 \mathrm{~cm}^{2}$ ) and there was mild to moderate tricuspid regurgitation (fig 1). The estimated pulmonary artery pressure was, however, grossly increased at about $100 \mathrm{~mm} \mathrm{Hg}$ and the interventricular septum was flattened suggesting pressure overload of the right ventricle (fig 2). The patient was admitted for close monitoring and a decision on further management. An oral diuretic (furosemide (frusemide) $40 \mathrm{mg}$ once daily) was initiated. Echocardiography repeated after two doses of diuretic showed a dramatic reduction in pulmonary artery pressures to about $25 \mathrm{~mm} \mathrm{Hg}$ (fig 3). The baby was delivered successfully by elective caesarean section at 37 weeks' gestation with invasive monitoring of the mother's pulmonary pressures. There were no complications.

\section{DISCUSSION}

Rheumatic mitral stenosis is the most common clinically significant cardiac abnormality seen in pregnant women worldwide. Stenosis of the mitral valve obstructs left ventricular filling resulting in increased left atrial pressure and reduced cardiac output. In severe mitral stenosis, pulmonary hypertension, pulmonary oedema, and right ventricular failure may develop. During pregnancy several haemodynamic changes exacerbate the cardiovascular aberrations associated with mitral stenosis. Intravascular volumes increase by up to $50 \%$ in the last trimester resulting in increased left atrial pressure and increased pulmonary venous filling, ${ }^{1}$ and increased heart rate during pregnancy reduces left ventricular diastolic filling time. During natural labour cardiac output and blood pressure increase with uterine contractions, and pulmonary artery catheter measurements during labour record significant increases in left atrial pressure. ${ }^{2}$ Immediately after delivery cardiac filling pressures increase dramatically due to vena caval decompression and return of uterine blood.

Pulmonary hypertension is associated with greatly increased maternal risk and moderately increased neonatal risk, with peripartum mortalities of $30-56 \%$ and $10-13 \%$, respectively. ${ }^{3}$ Elective caesarean section is therefore appropriate in conditions where pulmonary pressures are increased. Severe mitral stenosis with significant symptoms is associated with increased maternal and neonatal mortality $\left(3.5 \%\right.$ and $7.5 \%$, respectively, in one large series $\left.{ }^{4}\right)$ and may require balloon mitral valvuloplasty. ${ }^{5}$ In this high risk group mortality and morbidity increases incrementally with maternal functional class and severity of stenosis. ${ }^{67}$ Mortality among pregnant women with mild or moderate mitral stenosis and minimal symptoms, however, is less than $1 \% .{ }^{8}$ Therefore management of asymptomatic patients with mild to moderate mitral stenosis is usually conservative, with

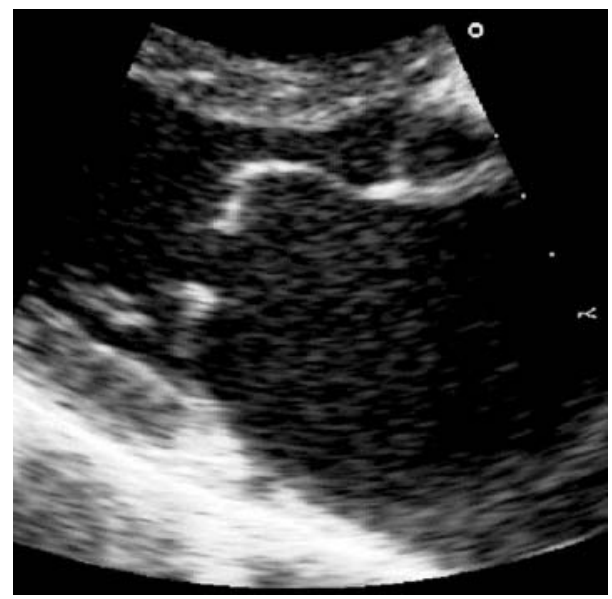

Figure 1 Transthoracic echocardiogram at 36 weeks' gestation. Long axis view of the rheumatic mitral valve showing classic doming of the leaflets in diastole. 

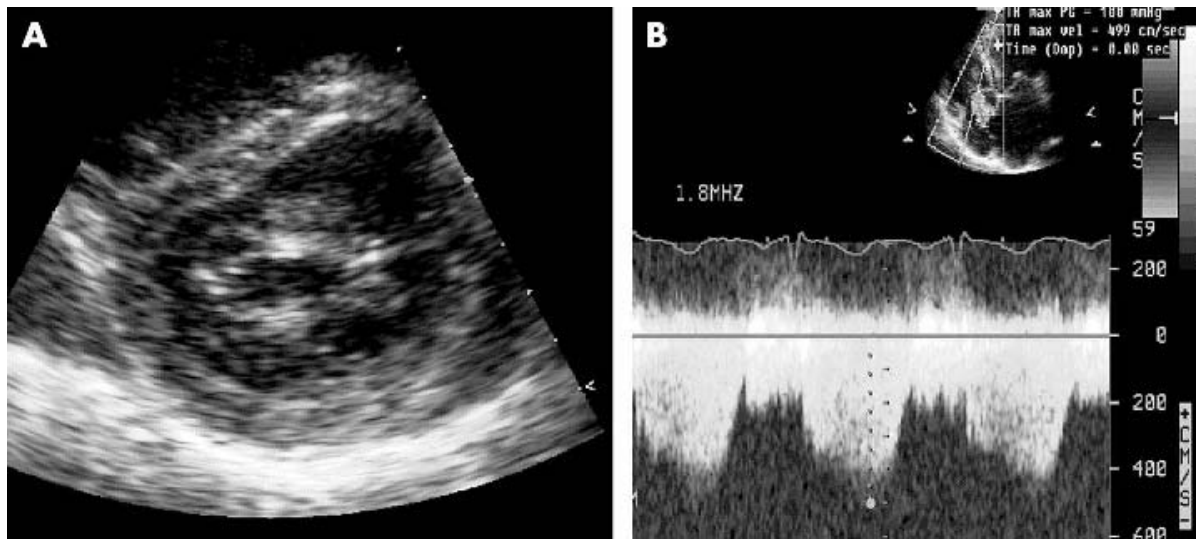

Figure 2 (A) Short axis view of left ventricle with flattening of the interventricular septum secondary to right ventricular pressure overload. (B) Continuous wave Doppler across the tricuspid valve showing peak velocities of $500 \mathrm{~cm} / \mathrm{s}$.
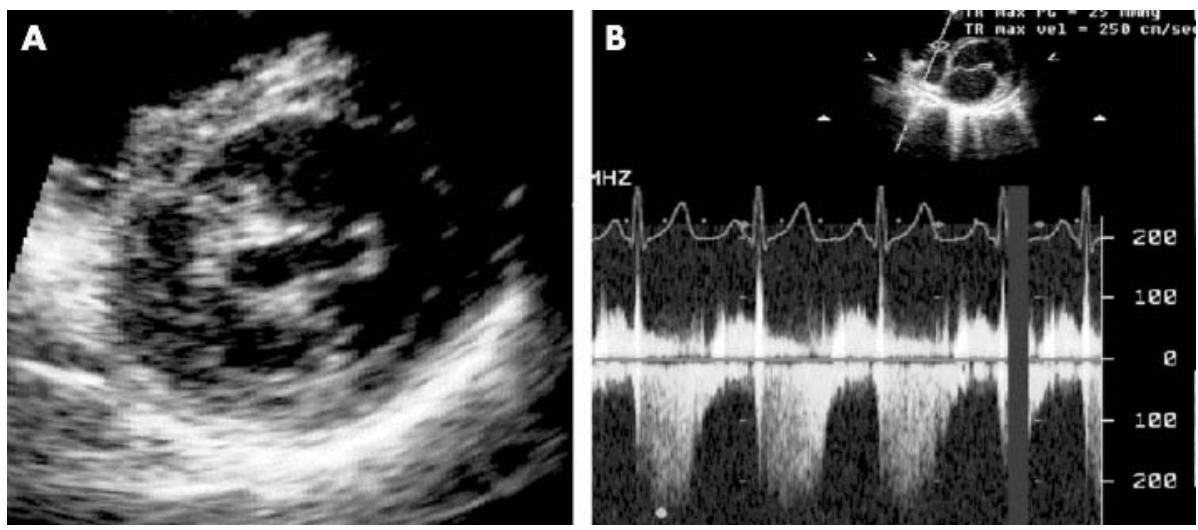

Figure 3 Repeat transthoracic echocardiography after diuretic treatment shows $(A)$ resolution of septal flattening and (B) reduction in tricuspid regurgitation peak velocities to $250 \mathrm{~cm} / \mathrm{s}$.

diuretics and $\beta$ blockers recommended to minimise volume overload and prolong the diastolic filling period, respectively, if symptoms develop during pregnancy.

This case illustrates the dramatic physiological impact of volume overload and diuresis on pulmonary pressures in the peripartum setting in a patient with moderate mitral stenosis.

\section{Authors' affiliations}

A Siva, A M Shah, Department of Cardiology, Kings College Hospital, London, UK

Correspondence to: Dr Anjana Siva, Department of Cardiology, Kings College Hospital, London SE5 9PJ, UK; anjana.siva@kcl.ac.uk

Accepted 5 October 2004

\section{REFERENCE}

1 Bonica JJ, McDonald JS. Principles and practice of obstetric analgesia and anesthesia. Baltimore: Williams \& Wilkins, 1995.

2 Clark SL, Phelan JP, Greenspoon J, et al. Labor and delivery in the presence of mitral stenosis: central hemodynamic observations. Am J Obstet Gynecol 1985; 152:984-8

3 Weiss BM, Zemp L, Seifert B, et al. Outcome of pulmonary vascular disease in pregnancy: a systematic overview from 1978 through 1996. J Am Coll Cardiol 1998:31:1650-7.

4 Sawhney H, Aggarwal N, Suri V, et al. Maternal and perinatal outcome in rheumatic heart disease. Int J Gynaecol Obstet 2003;80:9-14.

5 Fawzy ME, Kinsara AJ, Stefadouros M, et al. Long-term outcome of mitral balloon valvotomy in pregnant women. J Heart Valve Dis 2001;10:153-7.

6 Silversides CK, Colman JM, Sermer M, et al. Cardiac risk in pregnant women with rheumatic mitral stenosis. Am J Cardiol 2003;91:1382-5.

7 Barbosa PJ, Lopes AA, Feitosa GS, et al. Prognostic factors of rheumatic mitral stenosis during pregnancy and puerperium. Arq Bras Cardiol 2000;75:215-24.

8 Clark SL. Cardiac disease in pregnancy. Crit Care Clin 1991;7:777-97. 